\title{
LITERATURA E INTELECTUALIDADE: AS FACETAS INTELECTUAIS NA OBRA VIDA E MORTE DE M. J. GoNZAGA DE SÁ, DE LIMA BARRETO
}

\author{
LITERATURE AND INTELECTUALITY: THE \\ INTELECTUAL FACETS IN THE NOVEL VIDA E MORTE \\ DE M. J. GonZaga dE SÁ, Lima BARRETO \\ Cristiano Mello de Oliveira*
}

Resumo: O romance Vida e Morte de M. J. Gonzaga de Sá, de Lima Barreto, apresenta diversas passagens que apontam características da faceta intelectual e erudita do protagonista Gonzaga de Sá. O escritor compôs um verdadeiro amálgama de situações que evidenciam as muitas leituras alusivas a variados escritores de época, assim como demonstra grande capacidade para inventariar inúmeros afazeres e gostos que denotam a opção intelectual desses homens. Primeiramente, iremos fazer uma análise no sentido de promover uma introdução do objeto e montarmos a nossa problemática. Num segundo momento, pretendemos esboçar algumas das principais particularidades do romance Vida e Morte de M. J. Gonzaga de Sá. Num terceiro momento, desenvolveremos a análise dos fragmentos selecionados buscando identificar aqueles que mais evidenciem a temática do sujeito intelectual. Como lastro teórico, iremos dialogar parcialmente com: Sartre (1994), Bobbio (1996) e Said (2008), cada qual ao seu modo. A contribuição desse artigo visa despertar novas pesquisas sobre uma obra literária pouco lembrada pela crítica literária.

Palavras-chave: Intelectual. Literatura Brasileira. Vida e Morte de M. J. Gonzaga de Sá. Lima Barreto.

Abstract: The book Vida e Morte de M. J. Gonzaga (Life and Death by M. J. Gonzaga) de Sá has many passages that represent features of the intellectual and scholar protagonist Gonzaga de Sá. The writer Lima Barreto wrote a true amalgam of situations that indicate the readings of many writers of the time as well a great capacity to record the affairs and tastes that demonstrate the intellectual choice of these men. First, an analysis is done in order to introduce the object of study and the problem. Next, some of the main peculiarities of the romance Vida e Morte de M. J. Gonzaga de Sá are outlined. The third step is the analysis of the fragments selected

\footnotetext{
* Mestre em Literatura pela UFSC, doutorando em Literatura pela UFSC, pesquisador CNPQ. E-mail: <literariocris@ hotmail.com>.
} 
in order to identify those that best depict the thematic of the intellectual subject. The article develops a theoretical dialogue with Sartre (1994), Bobbio (1996) and Said (2008). The paper aims to stimulate further research about a literary work that has received little attention from literary criticism.

KeYwords: Intellectual. Brazilian Literature. Vida e Morte de M. J. Gonzaga de Sá. Lima Barreto.

\section{Alguns pressupostos}

O crítico literário e também romancista Osman Lins, no seu livro Lima Barreto e o espaço romanesco (1978), especificamente no capítulo VII, intitulado "Vida e Morte de M. J. Gonzaga de Sá”, aponta a relevância de compreender a obra de Lima Barreto, quando diz: "Vida e Morte de M. J. Gonzaga de Sá oferece aspectos os mais atraentes ao amador de ficção, capaz de perceber certas soluções e singularidade" (LINS, 1978, p.113). Trata-se de erudição coberta de preocupações literárias instigantes e, ao mesmo tempo, constitui uma excelente sugestão investigativa para valorizarmos novas perspectivas da ideologia barretiana. Embora Osman Lins, autor de vários romances privilegie, em sua abordagem, elementos que caracterizam o espaço romanesco dessa obra, assim como as possíveis ligações com o contexto histórico da cidade do Rio de Janeiro (assunto que o pesquisador retoma ao longo de algumas páginas), percebe-se que seu texto oferece vários desdobramentos que buscam o alicerce daquilo que será a característica primordial na feitura do personagem Gonzaga de Sá: "O interesse de Gonzaga de Sá pelo estudo é também introduzido como um traço favorável da sua personalidade [...]" (idem, p.114). Em suma, é a partir desse mote enviesado que iremos para uma análise mais direcionada.
É difícil escapar à tentação de esmiuçar os escritos de Lima Barreto, o qual, possuidor de uma imbatível retórica militante e de um estilo um tanto de caráter social, mesmo no desempenho frenético de ser cronista de jornal de época, sabia fisgar novos leitores e compor a sua ficção em plena República Velha. Podemos crer, quando o assunto é levantar alusões às obras lidas e consultadas, que Lima atinge um grau bastante satisfatório, tendo em vista as variadas fontes de que se embebeu o seu discurso romanesco. "A habilidade de Lima Barreto em trabalhar com dados históricos é admirável. Em poucas linhas ele situa o leitor em uma realidade histórica rica que se esconde por trás de toda a atmosfera de mistificação que envolve o conto." (MARINS, 2004, p.226). O escritor carioca era frequentador assíduo da Biblioteca Nacional e um contumaz leitor dos compêndios universais de filosofia, história universal e literatura. Não foi à toa que o seu último e póstumo livro Diário no Hospício recebeu fortes influências e correlações da obra Recordações da Casa dos Mortos (2008), do escritor russo Fiodor Dostoievski. E resta destacar que Lima foi uma espécie de intelectual autodidata e canalizador de muitos projetos culturais (linguagem suburbana, estilo caricato e cômico, entre outros) que antecipou muito daquilo 
que outros escritores confeccionaram posteriormente nos seus romances.

A obra Vida e Morte de M. J. Gonzaga de Sá (BARRETO, 1969d), escrita no ano de 1918, impõe um olhar mais aguçado do pesquisador aos tipos intelectuais que formulam a conjuntura desse acurado romance. Publicada no ano de 1919 pelo escritor e editor Monteiro Lobato, a narrativa é, grosso modo, toda investida de lances memorialísticos e alusivos ao contexto histórico e social do último quartel do século XIX e do primeiro do século XX. No decorrer dos acontecimentos que entremeiam o romance são realizados intensos diálogos entre Gonzaga de Sá e o narrador Augusto Machado ${ }^{1}$. A obra não possui um enredo muito bem definido, e tudo acaba girando em torno da personalidade e das vontades particulares do personagem autocentrado Gonzaga de Sá. Muitos desses conflitos são narrados pelo seu fiel amigo Augusto Machado de maneira filosófica, buscando questionar a sobrevivência de um homem espiritual no meio de uma sociedade absurda e incoerente com seus próprios princípios. O romance possui como cenário a oleogravura dos variados rincões da cidade do Rio de Janeiro, ou seja, a pintura é fértil e o olhar sempre demasiadamente imagético e genuíno, pois Lima acrescentara com sua criativa imaginação toques de grande sensibilidade aos seus escritos. "Todo o Gonzaga

\footnotetext{
1 O trecho adiante esclarece o inicio da decisão do narrador Augusto Machado em contar os fatos da vida do protagonista: "De Gonzaga de Sá, vou contar-lhe as suas cousas íntimas e dizer-lhes, antes de tudo, como morreu, para fazer bem ressaltar certos trechos e particulares que serão mais tarde contados, de sua bela obscuridade. Narremos os fatos." (BARRETO, 1969d, p.38)
}

de Sá decorre na cidade do Rio de Janeiro, onde nasceram e residem as personagens centrais." (LINS, 1978, p.118). Enfim, o romance apresenta muitos tópicos históricos e sociais ao clima intelectual de época.

$\mathrm{Na}$ verdade, o protagonista Gonzaga de Sá perfaz aquele individuo que valoriza as crenças intelectuais, o culto à sabedoria como fator de crescimento espiritual. Novamente teremos as palavras de Osman Lins: "Gonzaga de Sá, livro acentuadamente intelectual, nada tem entretanto de um romance de tese, nada quer provar, não se resolve ao longo de suas páginas equação nenhuma." (idem, p.116) Sá é devoto das crenças populares, das aproximações do povo e ao mesmo tempo muito desconfiado do casamento acabado e ajeitado pela sociedade. Paradoxalmente, Sá se apegava ao universo religioso por voluntariedade $\mathrm{e}$ a proximidade com Deus sem pretensão de ser reconhecido pelo público fiel da própria igreja, ou seja, era um homem "antimonástico". De igual modo, Sá faz aquele tipo de personagem que busca uma contemplação nos livros e na sabedoria enciclopédica tão pregada pelo famoso protagonista Policarpo Quaresma. Em suma, o protagonista é um contumaz leitor de variados livros e revistas importadas, buscando ser aquele homem de letras que direciona sua vontade para algo inalcançável, messiânico e quase utópico. Para começar, pertence à Secretaria dos Cultos², espécie de local burocrático

2 O fragmento que segue marca muito bem a caracterização dessa distinta secretaria: "Pouca gente conhece a Secretaria dos Cultos e tem notícia dos seus serviços. É de admirar que aconteça isso, porquanto, penso eu, se há secretaria que deva merecer o respeito 
onde muitos partícipes apreciam o hábito exagerado da leitura e da procura por materiais inéditos sobre vários assuntos.

Pesquisar; ler; conhecer; analisar; observar; examinar; provavelmente esses seriam os verbos mais utilizados pela pena de Lima Barreto durante esse intenso relato da vida do protagonista Gonzaga de Sá, através das andanças pela cidade do Rio de Janeiro. $\mathrm{O}$ questionamento brota espontaneamente: como sobrepor tantos estudos e conhecimentos buscando uma aproximação com a sociedade de época? Revistas nacionais e importadas, jornais, livros, compêndios, cadernos de anotações são os variados meios culturais para percorrer esse itinerário intelectual serpenteado tão cansativo e longo. "O Rio de Janeiro oferecia pois um campo ímpar de atuação dos intelectuais em um país pobre e quase que totalmente analfabeto." (SEVCENKO, 1983, p.94). Nesse sentido, nas leituras das revistas importadas francesas, magazines em língua estrangeira, Gonzaga de Sá, com sua alma erudita, alimenta boa parte do percurso de sua vida e repousa no descanso do seu pensamento, nos mais variados episódios e acontecimentos, buscando levantar profundos aspectos culturais. "Gostava Gonzaga de Sá muito de revistas. [...] Assinava a Revue, o Mercure, a Revue Philosophique; mas, de todas, a Revue des Deux Mondes é a que mais queria e citava." (BARRETO, 1969d, p.51).

Ora, possivelmente foram mais de cinco livros lidos arduamente desses distintos meios culturais, mas, ao mesmo tempo,

e a consideração da nossa população é a dos cultos". (BARRETO, 1969d, p.35). transmissores de conhecimentos que vantajosamente serviram o protagonista Gonzaga de Sá no decorrer de suas longas etapas de sua vida espiritual. "Pelo livro, acompanhava o movimento das letras pátrias, com vivo interesse mas sem paixão. Lia o Figaro e repetia, em francês e de cor, várias pilhérias do Masque de Fer." (ibidem) Mesmo pela tamanha curiosidade intelectual dos livros lidos, Gonzaga de Sá e seus confiáveis meios culturais não deixaram ou não isolaram a possibilidade de expandir seus vastos conhecimentos para com os seus pares. Enfim, utilizar com vasta curiosidade esses meios culturais como fonte de conhecimento e inspiração sem ao menos almejar o título de doutor significava para Gonzaga escapar das vaidades humanas burguesas, deixando de lado o reconhecimento e a notoriedade. Em suma, Gonzaga pavimenta ao longo desse caminho espiritual as contradições sociais de época estabelecidas na cidade do Rio de Janeiro, buscando uma possível solução para a libertação de seus méritos, tanto para a sua satisfação pessoal, tanto para o acervo cultural nacional.

O pesquisador Marcos Vinícius Scheffel, na sua tese de doutorado Estações de passagem da ficção de Lima Barreto (2011), aborda as crônicas e os escritos da intimidade de Lima Barreto com o romance Vida e Morte de M. J. Gonzaga de Sá. No acurado estudo, Scheffel busca rastrear as principais pistas contidas nesses escritos, focando nas possíveis relações contidas no romance, consequentemente envergando para perquirir sobre a fortuna crítica de Lima Barreto. A pesquisa de Marcos Scheffel faz uso de uma gama extraordinária de estudiosos. Dentro do nosso 
raciocínio, o autor esmiúça e reitera alguns teóricos importantes sobre tal assunto, desde Osman Lins e Sonia Brayer, passando por Nicolau Sevcenko, atravessando Carlos Fantinati, entre outros importantes, para compreensão do tema. Acentuando os entraves criados por alguns teóricos, problematizando algumas leituras, ele delineia as reflexões mais expressivas, como exemplo, a questão da intimidade do autor carioca, mote específico de sua investigação e envergamento epistemológico de sua tese. De igual modo, ele escolhe como objeto de análise os desdobramentos teóricos de Walter Benjamin, João Hernesto Weber, entre outros. Uma reflexão do estudioso se faz importante na sua tese atendendo a pertinência aqui estabelecida nesse artigo. "Em Vida e Morte, a comparação com os fragmentos do Diário é produtiva já que o romance incorpora dados típicos das leituras praticadas por Lima Barreto e chega ao limite extremo de agregar objetos da 'coleção' do autor à sua estrutura final." (SCHEFFEL, 2011, p.31).

Outra contribuição sobre a perspectiva do contexto histórico vivenciado por Lima Barreto, temos no acurado ensaio Literatura como missão (1983), de Nicolau Sevcenko, que estuda as obras dos escritores Euclides da Cunha e Lima Barreto para descrever problematicamente como se entrecruzam a prosa desses dois intelectuais. O espaço da Primeira República, repleto de acontecimentos importantes conjugados com a densa modernidade em expansão na cidade do Rio de Janeiro, é o pano de fundo da análise de Nicolau Sevcenko. Historiador contumaz e perspicaz, Sevcenko aborda as nuanças literárias que fizeram parte do frenético expediente de ambos os escritores, buscando evidenciar que tanto a História quanto a Literatura caminham no mesmo percurso narrativo. Ao concluir suas análises sobre o contexto dos séculos XIX e XX, Sevcenko escreve: "Os fenômenos históricos se reproduziram no campo das letras, insinuando modos originais de observar, sentir, compreender, nomear e exprimir. [...] Poucas vezes a criação literária esteve tão presa à própria epiderme da história tout court." (SEVCENKO, 1983, p.30). Ao que tudo indica, o estudioso deixa nítido que o fio condutor do seu raciocínio é mostrar como que a literatura caminha em passos estreitos com a história, uma influenciando a outra, buscando diluir ao máximo suas fronteiras, fazendo uma favorável interação com o público leitor.

A aproximação do texto romanesco com personagens intelectuais sempre foi motivo para grandes escritores continuarem escrevendo e se entusiasmando cada vez mais com seus projetos literários. Romance com toques eruditos e ao mesmo tempo manejado com o espírito criativo, fortalecera o louvor de muitos romancistas que pregavam uma pureza mais sofisticada para o enredo de suas obras ficcionais. $\mathrm{Na}$ literatura brasileira uma safra de escritores ousou implementar fatores intelectuais no bojo das suas personagens, evidenciando também os seus gostos eruditos. Machado de Assis confeccionou citações eruditas, passagens bíblicas, imaginações frutíferas, através do gosto e da fala de suas personagens nos seus contos e romances. "Machado 
buscava um público leitor ainda em formação e que tinha muitas restrições ao incipiente romance nacional. [...] Com Lima não foi diferente. Dirigindo-se a uma gama de leitores mais diversificada e incluindo em seus textos personagens de estratos sociais mais amplos, o escritor fez uso da língua portuguesa mais condizente com seus leitores/personagens." (MARINS, 2004, p.215216). Isto é, as semelhanças e as diferenças servem para angariar as possíveis hipóteses que podem ser refletidas sobre tais escritores, tarefa importante para uma aprofundada pesquisa. Por outro lado, de forma relativa, Lima Barreto focaliza personagens que possuem notórios conhecimentos eruditos e intelectuais, observaremos que estes aparecem nos seus quatro romances, buscando evidenciar uma vontade espiritual ao cultivar leituras e os hábitos de guardar livros na sua residência.

Uma breve digressão elucidativa faz-se necessária e urgente: a galeria dos personagens de Lima Barreto ilustra e ecoa bem aquilo que aqui estamos buscando exemplificar: o romance Triste Fim de Policarpo Quaresma apresenta de maneira irônica o personagem Policarpo Quaresma evidenciando a sede de manter em sua residência um acervo grandioso de livros. "Sentado na cadeira de balanço, bem ao centro de sua biblioteca, o major abriu um livro e pôs-se a lê-lo à espera do conviva." (BARRETO, 2004, p.20), escreve o narrador barretiano evidenciando a natureza intelectual do protagonista Major Quaresma. Já no romance Clara dos Anjos, teremos o personagem Doutor Praxedes: "Por tê-la assim, julgou-se uma inteligência, um grande advogado, e pôs a frequentar cartórios, servindo de testemunha, quando era preciso, indo comprar estampilhas, etc., etc." (BARRETO, 1969a, p.23) - relata o narrador descrevendo as habilidades intelectuais do personagem. No romance Recordações do Escrivão Isaías Caminha teremos o personagem Isaías buscando aprimorar os seus conhecimentos para construir um futuro mais próspero como migrante na cidade do Rio de Janeiro. "Dediquei-me açodadamente ao estudo. Brilhei, e com o tempo foram-se desdobrando as minhas primitivas noções sobre o saber." (BARRETO, 1969c, p.02). Por último e exceção àquilo que aqui estamos exemplificando, no romance Numa e Ninfa observamos o personagem Numa envolvido com uma série de artifícios para fingir ser um intelectual atento: "Numa com a sua irremediável preguiça mental nem ao menos os autores que citava lia e deles compreendia alguma coisa. A sua atonia de inteligência requeria uma artificial alimentação intelectual e esta ainda não havia sido inventada." (BARRETO, 1969b, p.100), escreve o narrador ironizando a má vontade e inércia erudita de Numa em relação aos estudos.

$O$ presente artigo visa a investigar o acervo intelectual do personagem Gonzaga de Sá como fator preponderante da sua representação literária. Pretendemos ao longo desse percurso rastrear os principais liames do enredo dessa significativa obra seguindo a trilha do acervo intelectual, basicamente seguindo a personalidade intelectual de Gonzaga de Sá: cultivo ao conhecimento, vontade de aprimoramento constante, caráter da denúncia social, do intelectual combatente, da erudição e sede insaciável de adquirir conhecimentos humanísticos. 
Embora haja uma fortuna crítica sobre esta obra, nenhuma se dispõe a analisá-la sob esse prisma tão original e profícuo. Diante de tal perspectiva, possivelmente podemos orquestrar a seguinte problemática: como o narrador barretiano consegue articular com tamanha habilidade toda essa conjuntura erudita nas suas personagens? Por que Gonzaga de Sá desejou ser um homem culto e aspirante das coisas de espírito? Quais seriam os trechos que evocam o enlace intelectual na obra Vida e Morte de M. J. Gongaga de Sá? Como é formado o escopo das principais características (aspectos linguísticos, históricos, denúncia social, aspectos urbanísticos da cidade do Rio de Janeiro) desse distinto romance? Como poderíamos interpretar esses diversos fragmentos? Como esses fragmentos se articulam e se desenvolvem no enredo da obra? Como o lastro teórico desenvolvido durante a análise dos fragmentos pode sofisticar e clarificar a interpretação? Por último, quais seriam as contribuições intelectuais de Gonzaga de Sá para a sociedade carioca de época? Ao longo desse percurso tentaremos responder essas indagações que se articularão como fio problematizador e ao mesmo tempo condensador de tais considerações.

\section{Características da obra Vida e Morte DE M. J. GoNZAGA DE SÁ}

O ilustre narrador Augusto Machado resolve narrar à história do seu grandioso amigo Gonzaga de Sá e expor ao público leitor suas lembranças de natureza biográfica e intelectual. Ao que tudo indica, Augusto é aquele tipo de pessoa que admira muito o inseparável companheiro Gonzaga. O mesmo sabe como nenhum outro homem as variadas vaidades do próprio amigo, ora faz uma alternância entre as lembranças, ora sobre as profundas reflexões. A esse respeito, "A causa mais importante, todavia, prende-se à natureza mesma do romance, circunscrito à descrição dos encontros e deambulações de Gonzaga e Machado através do Rio de Janeiro, à transcrição do que pensam sobre a vida e a morte [...]" (LINS, 1978, p.128), observa Osman Lins. Por outro lado, o narrador Augusto Machado, de caráter extremamente social, ao oposto do protagonista Gonzaga, que era uma pessoa com caráter relacionado à própria situação da morte e à decadência, está preso à própria vida. Ao contrário do fiel amigo que sempre buscou o isolamento como forma de comungar seu conhecimento durante sua vida de funcionário público e silenciou-se em sua erudição, o narrador Augusto Machado quer fortalecer seus meios sociais e consequentemente manter contato com seus pares. Enfim, o substrato intelectual encontrado e refletido em ambos os personagens desse romance é material que merece uma investigação mais aprofundada.

Seguindo um raciocínio interessante teremos o livro Lima Barreto e o fim do sonho republicano (1995), da pesquisadora Carmen Lúcia Negreiros de Figueiredo. Canalizando seu objeto de estudo no contexto político republicano, especulando com grandes resultados, na explanação da obra barretiana, a estudiosa compõe um verdadeiro mosaico bibliográfico explicativo. A autora logo na introdução faz uma advertência, em que salienta a importância de estudar 
a obra do romancista carioca sem cair nas tentações de cunho biográfico do próprio autor. O binômio humor/caricatura aparece demasiadamente nas suas reflexões evidenciando uma forte preocupação de Carmen em esclarecer tal perspectiva, apresentando várias exemplificações condizentes com o estilo da escrita barretiana.

As reflexões feitas por Gonzaga de Sá demonstram que, de um modo tão convincente quanto um filme com o seu ilusionismo, a realidade criara signos nos quais se projetam os atributos da personalidade humana. (FIGUEIREDO, 1995, p.80).

Compartilhamos com o fragmento da estudiosa que de forma acurada consegue angariar novas formas de enxergar o perfil interpretativo do protagonista do romance. Portanto, o conteúdo exercitado pela pesquisadora não chega a aprofundar tais dilemas da personalidade do protagonista Gonzaga, que seriam extremamente importantes para a investigação de outros estudiosos no assunto.

Reticências à parte, no âmbito da linguagem poética e do máximo das ricas potencialidades da língua portuguesa aplicadas à paisagem exótica e exuberante da cidade do Rio de Janeiro, Lima Barreto explora densamente tudo isso no seu M. J. Gonzaga de Sá. A começar pela variedade de detalhes pitorescos da poética Baía de Guanabara: "[...] calma face da Guanabara, ligeiramente crispada, naquela hora de efusão e confidência."; "Villegagnon boiava na placidez das águas, com seus muros brancos e suas árvores solitárias"; "O negro costão do
Pão de Açúcar dissolvia-se nas massas ondas da enseada."; "O mar espelhajante e móvel realçava a majestade e a firmeza da serrania e, em face da sua suntuosidade..."; "O poeta tinha razão; era verdadeiramente a grandiosa Guanabara que eu via!" (BARRETO, 1969d, p.39). Não obstante, os aspectos contemplativos citados nos escritos de M. J. Gonzaga de Sá extraem a genialidade literária e linguística amalgamando os elementos poéticos do romancista carioca. Em suma, uma série de incrustações ousadas que partem da simplicidade do lado artístico e finaliza na observação da vida do Rio de Janeiro tão amada de Lima Barreto e suas personagens.

Outro aspecto relevante da linguagem poética entrelaçada aos fatos históricos de época seria o apelo aos dados e datas de um verdadeiro compêndio do Brasil. Episódios que revelam o forte apoio documental e as crônicas daquele período que terminam sumariamente ou mesmo iniciam alguns desses escritos literários de M. J. Gonzaga de Sá. Por esse motivo as linhas ficcionais de Lima Barreto ficam sempre guarnecidas de um espírito original e criativo de fazer literatura histórica. Ao leitor mais conhecedor do estilo e da própria linguagem do romancista carioca é comum verificar nessas passagens um profundo grau de conhecimento de outras obras, assim como a prosa inovadora de um escritor ousado e determinado a "queimar os seus navios". ${ }^{3}$ Diversas passagens do romance Vida e Morte de M. J. Gonzaga de Sá

3 Expressão contida na palestra "O destino da Literatura”, proferida na cidade de Mirassol, interior de São Paulo. Revista Souza Cruz, Rio de Janeiro, ns. 58-59, out-nov. 1921. Apud BARRETO, Lima. Impressões de leitura. Op. cit. p.55 56. 
são enriquecidas pela linguagem de registro ou aquela que narra acontecimentos vivenciados sob um efeito nostálgico de sabedoria aos marcos mais importantes. Sendo assim, o efeito predatório da implantação do regime republicano em território brasileiro acontece de forma alusiva. "As suas reminiscências de história não lhe davam de pronto a ideia nítida do que fosse república." Em outro episódio identificaremos o narrador diante de uma passagem bem ilustrada aos termos nacionalistas: "Vi regimentos, vi batalhões, luzidos estados-maiores, pesadas carretas, bandeiras do Brasil, sem emoção, sem entusiasmo, placidamente a olhar tudo aquilo, como se fosse uma vista de cinematógrafo." (BARRETO, 1969d, p.51) Em suma, entre tantos outros aspectos históricos que ocupariam uma lista grandiosa de fragmentos que não certamente caberiam em um artigo tão breve.

Por outro lado, para garantir uma linguagem ainda mais distinta possivelmente denunciadora das facetas sociais que se diziam democráticas na época, as frases e os vocábulos do narrador barretiano não poupam esforços de inovar atingindo um grau da invenção e da militância intelectual. Muitas dessas palavras e expressões são lapidadas ao longo de sua maturação de escritor capaz de transformar sua voz e suas variadas observações dos aspectos sociais para uma maneira romanesca de demonstrar suas inquietações ao modelo vigente. É possível que Lima Barreto tenha inovado na linguagem durante alguns dos seus percursos de criação, facilitando assim sua invenção e criatividade que futuramente resultaria na ampliação dos diálogos de caráter social existentes na prosa de M. J. Gonzaga de Sá. Alguns trechos: "A nossa insignificância nas artes do desenho é manifesta. Não pecará tanto quanto à execução, mas no que toca à imaginação criadora é cousa que não se discute." (BARRETO, 1969d, p.53), escreve o narrador ilustrando a notória carência da falta de criatividade dos nossos artistas. Ora, o narrador e a matéria narrada se aproximam em demasia e ainda constrói uma crítica bastante construtiva sobre os efeitos nocivos da sociedade em apenas valorizar as profissões da elite e desprezar aquelas ligadas às humanidades. "Há muita gente que, sem queda especial para médico, advogado, engenheiro, tem outras aptidões intelectuais, que a vulgaridade do público brasileiro ainda não sabe apreciar, animar e manter.", (idem, p. 48) novamente escreve o narrador barretiano com um olhar mais íntimo e realista dos problemas da sociedade tão hipócrita de época. Enfim, muitas dessas denúncias de Lima Barreto são indispensáveis para um bom historiador preocupado em compreender o Brasil de época, já que permanecem na resistência da passagem do tempo.

Essas denúncias de caráter social também atingem a amplitude jurídica do estado e o sistema político da época. Por esse motivo, é notável que Lima consiga articular de maneira disfarçada através da fala das suas personagens uma série de situações intransigentes ao gasto ineficiente do erário público da época, denunciando a péssima consciência desses políticos para o devido uso e investimento necessário a população. Muitas 
dessas passagens ilustram que a literatura de Lima não cumpria apenas um olhar de deleite da sociedade de época, mas a função de questionar as instituições vigentes e problematizar de uma maneira mais consciente, outorgando a sua formulação de critérios e juízo. Por isso sua personagem Gonzaga explica que a maneira que o: " [...Barão do Rio Branco] faz do Rio de Janeiro a sua chácara... Não dá satisfação a ninguém... Julga-se acima da Constituição e das leis... Distribui o dinheiro do Tesouro como bem entende... É uma espécie de Roberto Walpole... O seu sistema de governo é a corrupção..." (BARRETO, 1969d, p.70). Ora, o fragmento apresentado demonstra um alto grau de descontentamento por parte de Lima e outros pares amigos da mesma época.

Portanto, Lima tinha certeza da problemática enfrentada e fazia o possível para denunciá-la sob a luz dos desafios enfrentados. O efeito dessa paixão e desse aspecto revolucionário como fio condutor para romper de forma desinteressada as contradições de época é muito bem explicado pelo fragmento transcrito abaixo, de Edward Said:

Os verdadeiros intelectuais nunca são tão eles mesmos como quando, movidos por paixões metafísicas e princípios desinteressados de justiça e verdade, denunciam a corrupção, defendem os fracos, desafiam a autoridade imperfeita ou opressiva. (SAID, 2008, p.24).

A rigor, se fôssemos aqui explorar e abstrair algumas frases e fragmentos na obra Vida e Morte de M. J. Gonzaga de Sá, iríamos brevemente remontar a uma série de correlações aos meios progressistas urbanísticos de época. Ao que tudo indica parece que o escritor Lima Barreto usa a fantasia e o figurino daquele urbanista e arquiteto sensato e determinado a verificar os problemas da cidade do Rio de Janeiro buscando pequenas soluções e elucubrações necessárias que poderiam ajustar e melhorar vários tipos de serviços públicos. O fragmento ilustra muito bem: “... Providência, Pinto, Nheco - ficam muito distantes do Campo de Santana, que está na vertente oposta; mas com aperfeiçoamento da viação, abertura de túneis, etc., todos os inconvenientes ficarão sanados." (BARRETO, 1969d, p.65), escreve em tom profético retratando que no futuro haveria grandes túneis que sanariam os problemas. Ora, para bom leitor da geografia da urbs carioca, Lima antecipa e diagnostica uma espécie de premonição para futuras melhorias que de fato ocorreram em décadas posteriores. Em outro momento, teremos o imbricamento dessa questão bem explicado: "É que o Rio de Janeiro não foi edificado segundo o estabelecido na teoria das perpendiculares e oblíquas. Ela sofreu, como todas as cidades espontâneas, o influxo do local em que se edificou e das vicissitudes sociais por que passou, como julgo ter dito já.", (idem, p. 66) observa o narrador justificando a problemática existente diretamente relacionada aos condicionamentos naturais da geografia urbana carioca como fator dificultoso para o estabelecimento de grandes melhorias. Em suma, tais fragmentos evidenciam a maneira progressista e poética de todo o pensamento de um autor preocupado em descrever as incoerências 
de uma grande metrópole que se iniciava no seu processo de modernização.

3. ANÁlise das FACETAS INTELECTUAIS DO PROTAGONISTA M. J. GoNZAGA DE SÁ

Manuel Joaquim Gonzaga de Sá, homem determinado a cultivar o hábito da leitura e fazer disso a sua vontade espiritual, é cidadão comprometido com os conceitos de nação. Gradativamente, iremos observar no decorrer da linha evolutiva do romance que Gonzaga de Sá foi um sujeito que acumulou diversos tipos de conhecimentos, ou melhor, adquiriu sabedoria e habilidade para usá-la na medida certa e comungá-la com os seus discípulos de época. Em outras palavras, Sá foi um cidadão autodidata que compartilhava suas aptidões humanas buscando praticá-las no seio da sociedade em que vivia. O protagonista perfaz um perfil de caráter sábio e contestador das ideias vigentes daquele período. Algumas passagens, que iremos selecionar adiante, ilustram bem a vontade profunda do protagonista em conhecer os clássicos da literatura universal, da filosofia de época, das humanidades e expandir suas escolhas e conhecimentos para o progresso de sua vida espiritual.

Em um primeiro episódio, iremos verificar o narrador Machado tecendo alguns comentários nostálgicos sobre as preferências literárias universais do consagrado Gonzaga de Sá. Vejamos alguns desses detalhes que ilustram muito bem essa ótica de análise:

Logo me recordei, porém, dos meus autores - de Taine, de Renan, de M. Barres, de France, de Swift e Flaubert
- todos de lá, mais ou menos da terra daquela gente! Lembrei-me gratamente de que alguns deles me deram a sagrada sabedoria de me conhecer a mim mesmo, de poder assistir ao raro espetáculo das minhas emoções e dos meus pensamentos. (BARRETO, 1969d, p.78).

Do fragmento transcrito acima é oportuno resgatarmos os nomes dos escritores ao qual o narrador faz menção em relação à leitura dos clássicos estabelecidos pela vaidade intelectual. Todos esses nomes evocados mantêm a finalidade de ilustrar acuradamente o gosto pessoal e o critério de valor remetido a esses escritores tão consagrados. Como podemos verificar a lista desse cânone completa de forma indispensável a "sagrada sabedoria" de qualquer intelectual mais exigente e consciente de ter como pressuposto essa grandiosa bagagem literária. Além disso, a safra desses escritores descritos comporta um olhar mais respeitoso pela formação clássica de uma excelente literatura estrangeira. Ora, por esse motivo o aproveitamento dessas leituras realizadas por Sá condiciona um espírito mais sofisticado e atento às condições já consagradas da busca do autoconhecimento e determinação para uma vida mais emotiva. Algumas linhas adiante, iremos encontrar novamente o narrador Machado descrevendo através de algumas minúcias o conteúdo espiritual do protagonista Gonzaga de Sá. Vejamos alguns desses detalhes:

Gonzaga era desses homens cujo pensamento se transmite mal pelo escrever ou por outro instrumento qualquer de comunicação criado pela 
nossa humanidade. A sua inteligência não sabia dar logo um pulo da cabeça para o papel; e só a sua palavra viva, assim mesmo em palestra camarada, era capaz de dizer dele tudo o que lhe era próprio e profundamente seu. (BARRETO, 1969d, p.43).

A descrição, coberta de efeitos psicológicos, revela uma integridade com o espírito e a vida. A distinção do caráter de Sá faz ressoar aspectos comportamentais daqueles indivíduos que valorizam o culto e o hábito da leitura como fator nobre do progresso intelectual. Tirando o lado preocupado da insatisfação capitalista e consumista, Lima Barreto constrói uma personalidade exótica aos padrões do brasileiro de época, ironizando em forma caricatural, já que boa parte da população carioca não tinha nenhuma vontade ou aspiração ao conhecimento de sua história ou mesmo de sua memória. Tarefa um tanto complexa para os padrões de época? Obviamente que essa questão poderia ser relativizada, tendo em vista a forte vontade da maioria dos homens em atingir sucesso em curto prazo e se colocar financeiramente frente aos outros amigos competidores.

Em outro fragmento, a caracterização do personagem Gonzaga de Sá é ilustrada pela sua formação clássica e robustecida de fatores principiantes de uma sólida formação educacional. Vejamos os detalhes:

Manuel Antonio Gonzaga de Sá era bacharel em letras pelo antigo Imperial Colégio Dom Pedro II. Possuía boas luzes e teve sólidos princípios de educação e instrução. Conhecia psicologia clássica e a metafísica de todos os tempos. Comparava opiniões de Visconde de Araguaia com o senhor Teixeira de Mendes. (BARRETO, 1969d, p.47).

Neste excerto observamos grandes nuances daquela educação voltada a compreender o pensamento de época através das cadeiras clássicas do acervo cultural brasileiro. A começar pela tradição e qualidade do Colégio Dom Pedro II, que buscava modelar nos seus alunos um conhecimento mais aprofundado da realidade nacional e daqueles que exigiam adquirir conhecimentos de ordem e civilidade. A amplitude de conhecimentos ligados à área de humanas provavelmente fez com que Gonzaga de Sá projetasse uma condição básica para conhecer os aspectos humanísticos como fator essencial da riqueza do seu espírito. "O que caracteriza o intelectual não é tanto o tipo de trabalho, mas a função:" (BOBBIO, 2004, p.114). Esta citação de Norberto Bobbio (trabalhada em um contexto diferenciado) pauta a importância fundamental do papel público do intelectual, enquanto função a ser exercida por essa categoria, problematizada muito bem com a função desempenhada pelo personagem Sá. O maior problema é que Gonzaga de Sá fazia jus a sua incansável sabedoria como vontade e desejo de saciar sua sede de conhecimento. Ao que tudo indica, sem confundir autor com a obra, Lima Barreto também tinha uma vontade enorme de conhecer a fundo muitas áreas de conhecimento e junto a isso construir personagens que tinham quase o mesmo perfil. Vejamos alguns desses detalhes: 
A sua ânsia e a sua febre de conhecimento, tais como via nele, sempre a par do movimento intelectual do mundo, fazendo árduas leituras difíceis, deviam procurar transformar-se em obra própria, tanto mais que não era um repetidor e sabia ver fatos e comentar casos a seu modo. (BARRETO, 1969d, p.50).

Do excerto acima pinçamos apenas os vocábulos "ânsia” "febre”; "árduas" que direcionam um olhar mais solidário a sua real sede de conhecimento. Na tríade vocabular verificamos uma forte acepção de conhecer as humanidades a fundo por parte de Gonzaga de Sá. Tamanha complexidade intelectual e inquieta é mencionada pelo narrador desejando demonstrar que Gonzaga tinha a capacidade de transformar o seu conhecimento acumulado através de suas profundas reflexões. Curiosidade motivada em reconhecer que sua sabedoria ainda não estava pronta, todavia, precisava ser problematizada para fins do avanço científico. É lógico que, pela quantidade de leituras e direcionamentos intelectuais, Gonzaga sugere que o próprio narrador deveria o quanto antes elaborar seu próprio livro das formulações lidas e abstraídas ao longo das suas “árduas leituras.” A indagação surge: para que tanta sede de conhecimento? Dinheiro, fama, contatos com pessoas ilustres e importantes? Movimento que adiante iria atestar e condicionar uma resposta um tanto coerente e ao mesmo tempo desinteressada de projeções individualistas.

Mais tarde, porém, fiquei perfeitamente certo de que era só curiosidade intelectual, que o animava e mantinha nas suas leituras árduas [...]. (BARRETO, 1969d, p.50).

Ao enfatizar a determinada sede de conhecimento por Gonzaga de Sá e seu narrador Machado, podemos desdobrar certeiramente com aquilo que Jean Paul-Sartre tinha refletido em uma de suas conferências sobre a função do intelectual e suas vontades canalizadas para atingir o "universal", sem restrições. Isto é, o intelectual seria aquele sujeito que remaria através de sua total autonomia, conseguindo administrar conceitos indispensáveis ao crescimento humano. "O intelectual é, portanto, um técnico do universal que se apercebe de que, em seu próprio domínio, a universalidade ainda não está pronta, está perpetuamente a fazer." (SARTRE, 1994, p. 35). Ora, como podemos verificar o tiro certeiro do narrador Machado em dizer que Gonzaga de Sá era um intelectual voltado a alimentar sua curiosidade por simples vocação ao direcionamento espiritual acaba condizendo ao universalismo que Sartre atribui aos seus anseios. Em suma, os dizeres de Sartre acabam postulando um olhar mais amistoso e sensível para os desdobramentos da personalidade de Gonzaga.

De igual modo, respaldando consistentemente o nosso mote de leitura iremos ter novamente uma reflexão de Sartre em relação ao conhecimento amplo e dedicado desse mesmo intelectual sujeito a compreender, aos moldes de Gonzaga de Sá, os "princípios universais" da humanidade que direcionava o seu olhar. Vejamos algumas considerações de Sartre a esse respeito: 
O intelectual atua assim com base em princípios universais: todos os seres humanos têm direito a contar com padrões de comportamento decentes em matéria de liberdade e justiça da parte dos poderes ou das nações do mundo, e as violações deliberadas ou inadvertidas destes padrões têm de ser denunciadas e combatidas corajosamente. (SARTRE, 1994, p.28).

O vocábulo "intelectual" neste fragmento possui acepções que remetem a mentor, a proteção divina, a interdependência, a combatente, a excesso de responsabilidade devido aos fatores do seu próprio pensamento. Ora, como podemos verificar novamente nas palavras de Jean Paul-Sartre o intelectual é um ser humano voltado a compreender e denunciar aquilo que se encontra de injusto na sociedade. Ao que tudo indica, isso se assemelha perfeitamente às variadas passagens já explicitadas no corpo desse artigo. Além disso, o personagem Gonzaga de Sá, como já verificamos, foi um homem que possuiu vontade interna de viver sua vida com suas leituras, dedicando profundamente o seu tempo livre, agindo em boa fé e comunhão com seus principais ideais. O "comportamento decente" apontado por Sartre seria aquele que dificilmente aceita as contradições humanas como algo plenamente justificado e conformado, ou seja, luta em descobrir as "verdades" e as "contradições" tão enraizadas na sociedade. Por esse motivo, Gonzaga de Sá adquire conhecimento e sabedoria em função desinteressada ${ }^{4}$, ou seja, desmascara as principais

4 Sobre a função desinteressada de Gonzaga de Sá poderíamos brevemente sumariar com essa notável passagem do narrador: "Aliava a tudo isso, uma estóica incongruências e injustiças praticadas pelas autoridades insensíveis. A sensibilidade de Gonzaga era aquela que agia como: “[...] uma espécie de pura inteligência que via a vida e as suas instituições para lhe colher os aspectos contraditórios." (BARRETO, 1969d, p.136). Portanto, a nosso ver, Gonzaga de Sá foi aquele personagem que demonstrou genuinamente o seu amor pelas letras e pela pátria, evidenciando uma retórica vazia que era praticada pelas autoridades, assim como o próprio autor Lima Barreto demonstrou ao longo de sua breve vida.

No próximo fragmento iremos verificar o real propósito dos seus objetivos em relação à época. Percebemos que Gonzaga desejava compor um alicerce de conhecimentos que logicamente garantiria uma profissão mais pragmática e burocrática, consequentemente isso lhe tiraria toda a razão de sua fiel vontade espiritual de continuar compondo as suas reflexões. Aliás, podemos perceber através das páginas desse acurado romance que Gonzaga de Sá não completa o perfil daquele sujeito tão apaixonado pela burocracia. Gonzaga desejava continuar o seu afunilamento nos estudos intelectuais sem compromisso e, aliás, coberto de ousadias para reproduzir independentemente seus estudos. O foco seria estudar e ler sem desejar futuros ganhos imediatos e tampouco manter o senso estético da consagração da vaidade intelectual de época, como versa o narrador Machado,

Deixando de seguir um curso profissional qualquer, foi como se fugisse aos programas, para ler com mais

$\overline{\text { despreocupação da notoriedade, ou melhor, da posição }}$ fácil e barulhenta." (BARRETO, 1969d, p. 47) 
ordem e método os autores, ao jeito de quem vai escrever uma memória ou um Felix Alcan, de sete francos e cinquenta. Fez o curso à antiga, em matérias isoladas, abandonando o seriado das universidades medievais, tradição que, dominando nas nossas faculdades, faz estabelecer os mais absurdos encadeamentos de matérias e disciplinas nos seus anos ou séries. (BARRETO, 1969d, p.51).

A frase "curso profissional qualquer" já alimenta semanticamente critérios de valor e força. Isto é, o protagonista Gonzaga não desejava nada que lhe fosse imposto ou influenciado por determinada pessoa próxima. Ao que tudo indica, Gonzaga não parecia muito satisfeito com as imposições profissionais no tocante às carreiras mais glamorosas de época, por isso reconduz o seu olhar e sua formulação de juízo, fazendo ressoar um comportamento de uma pessoa altamente esclarecida para fortalecer a sua opinião convicta da realidade que já conhecia muito bem. Como salienta novamente o crítico Edward Said: "Uma das tarefas do intelectual consiste no esforço em derrubar os estereótipos e as categorias redutoras que tanto limitam o pensamento humano e a comunicação." (SAID, 2008, p. 14). Obviamente que, se considerássemos as entrelinhas da citação transcrita acima, baseado no objeto narrado, iríamos interpretar que Gonzaga não fazia pouco caso daquelas profissões mais afastadas do meio intelectual, porém não chegava a se identificar pessoalmente com o que era reproduzido de maneira massacrante.
Fechando nosso raciocínio, durante a leitura desses fragmentos verificamos que o narrador delegado por Lima Barreto não evidenciou apenas um certeiro diagnóstico da personalidade intelectual de Gonzaga de Sá, e sim buscou chamar atenção para outras especificidades menos radicais. Na verdade, essa paixão construída pela literatura e fazer dela instrumento de arte necessário para comungar seus desejos de caráter social atribuído à denúncia daquilo que observava de mais injusto na sociedade brasileira, especificamente a cidade do Rio de Janeiro, fez com que Lima ousasse nos seus escritos por uma ideologia mais coerente. Sobretudo, o escritor carioca desvencilha o provincianismo acomodado à brasileira que se perpetuou durante décadas e que, sobretudo, iria diante dessas passagens "abrir cortinas" para novos horizontes. Os aspectos filosóficos tomam conta do diálogo longo entre ambos os locutores (Machado e Gonzaga) e faz com que o leitor possa refletir sobre os critérios para a escolha daqueles que mais representam as humanidades. Gonzaga sugere que todos aqueles sentimentos emotivos que temos no âmago da nossa personalidade individual fluem como um aspecto bastante ligado ao saber fechado que dificilmente será tocado por alguém. A questão parece óbvia, mas impõe uma perspectiva mais crítica de análise ao refletirmos que Gonzaga fazia honra para representar seu caráter forte e ao mesmo tempo quase ambivalente nos seus comentários orais. Enfim, tamanha trajetória intelectual que postergou muito daquilo que desejava guardar enquanto sujeito persuasivo nas suas decisões. 


\section{ConsideraÇões finais}

Literatura com viés social, intelectual e revolucionário, mas não tendo a intenção de afastar a arte das reais intenções do artista, em outras palavras, a arte de Lima Barreto era aquela primeiramente disposta a representar o estético e o sublime para depois atingir outros patamares relevantes. A arte literária para Lima Barreto deveria representar o lado social e intelectual, como já mencionamos em linhas anteriores. Por esse motivo, a arte literária não deveria ficar estagnada e deveria refletir abertamente as contradições de época, sem ser panfletária ou com intenção apenas de incomodar uma minoria que fosse antagonista aos projetos de nação. Podemos postular que para o romancista carioca à medida que fossem cessando as batalhas políticas, a ganância e o egoísmo acentuado do homem - numa sociedade onde não haja grandes abismos entre as classes ou extinga o próprio conceito de classes -, as paixões pela arte e o acesso à cultura iriam fomentar novas esperanças e perspectivas de vida para aqueles que ainda continuam à margem do processo criativo e dos bens que a burguesia ainda detém.

As contribuições intelectuais deixadas por Lima Barreto na obra Vida e Morte de M. J. Gonzaga de Sá projetam uma espécie de consciência atual aos problemas que são históricos e iluminam possíveis reformulações nas instituições que elaboram as políticas de combate em favor de uma educação de qualidade nesse país. Seus escritos deixaram uma espécie de semente para o valor da erudição e do espírito intelectual desinteressado representado muito bem pelo seu personagem Manuel Joaquim Gonzaga de Sá. Provavelmente, o romance poderá ser lido como documento, reportagem dos episódios que cercavam a cidade do Rio de Janeiro à luz do seu sincero pensamento. Talvez Lima Barreto, sem saber ou tomar consciência, refez antecipadamente todo um documentário de época sobre o comportamento desse sujeito intelectual frente às condições precárias. Essa leitura não significa a única maneira de verificarmos esses problemas emergentes da falta de vontade intelectual de muitas pessoas, mas impõe um olhar mais para aquilo que aqui estamos buscando comprovar através desse breve artigo. Portanto, o certo é que ainda existem muitas inesgotáveis maneiras de explorar o manancial desse grandioso romance, porém postulamos que lançamos algumas sementes que certamente irão brotar no solo dos estudos literários de outros centros de investigação.

\section{REFERÊNCIAS}

BARBOSA, Francisco de Assis. A vida de Lima Barreto. Rio de Janeiro: José Olympio, 2002. BARRETO, Lima. Clara dos Anjos. Rio de Janeiro: Brasiliense, 1969a.

Numa e Ninfa. Rio de Janeiro: Brasiliense, 1969b.

\section{Recordações do escrivão Isaías}

Caminha. São Paulo: Brasiliense, 1969c.

Triste fim de Policarpo Quaresma, Curitiba: UFPR, 2004.

Vida e morte de M. J. Gonzaga de Sá. Rio de Janeiro: Brasiliense, 1969d.

BOBBIO, Noberto. Os intelectuais e o poder. São Paulo: Editora da Unesp, 1996. 
DOSTOIEVSKI, Fiodor. Recordações da casa dos mortos. São Paulo: L\&M Pocket, 2008.

FANTINATI, Carlos Erivany. O profeta e o escrivão: estudo sobre Lima Barreto. São Paulo: Hucitec, 1978.

FIGUEIREDO, Carmen Lúcia Negreiros. Lima Barreto e o fim do sonho republicano. Rio de Janeiro: Tempo Brasileiro, 1995.

LINS, Osman. Lima Barreto e o espaço romanesco. São Paulo: Ática, 1978.

MARINS, Álvaro. Machado e Lima: da ironia à sátira. Rio de Janeiro: Utópos, 2004.

SAID, Edward. Representações do intelectual. São Paulo: Companhia das Letras, 2008.

SCHEFFEL, Marcos Vinicius. Estações de passagens da ficção de Lima Barreto. Florianópolis, 2011 (Tese de Doutorado)

SARTRE, Jean-Paul. Em defesa dos intelectuais. São Paulo: Ática, 1994.

SUSSEKIND, Flora. Cinematógrafo de letras.

São Paulo: Companhia das Letras, 2006.

Recebido para publicação em 3 agosto 2011. Aceito para publicação em 5 jul. 2012. 